\title{
HYDROXYAPATITE COATING OF THREADED PINS ENHANCES FIXATION
}

\author{
G. MAGYAR, S. TOKSVIG-LARSEN, A. MORONI \\ From the University Hospital, Lund, Sweden and the Rizzoli Orthopaedic Institute, Bologna, Italy
}

We measured the insertion and extraction torque forces in a randomised study of 76 external fixation screws in 19 patients treated by hemicallotasis for osteoarthritis of the medial side of the knee. The patients were randomised to have either standard tapered screws (Orthofix $6 / 5 \mathrm{~mm}$ ) or the same screws with hydroxyapatite (HA) coating. One patient had two standard and two HA-coated screws. All patients had an anterior external fixator (Orthofix T-garche), with two screws in the proximal tibial metaphysis parallel to and about $2 \mathrm{~cm}$ below the joint surface and two in the tibial diaphysis.

The mean torque forces for insertion of the standard screws were $260 \mathrm{Ncm}$ for the proximal to medial screw, 208 for the proximal to lateral screw and 498 and $546 \mathrm{Ncm}$ for the diaphyseal pins. The corresponding forces for the HA-coated pins were not significantly different. The torque forces for the extraction of the standard pins were $2 \mathrm{Ncm}$ for the proximal pins, 277 and $249 \mathrm{Ncm}$ for the distal pins and 482, 478, 585 and $620 \mathrm{Ncm}$, respectively $(\mathrm{p}<0.005)$ for the HA-coated pins.

All 18 of the metaphyseal standard screws were loose at extraction (extraction force $<20 \mathrm{Ncm}$ ), but only one of the HA screws in the metaphysis was loose. In the diaphysis the standard screws lost about $40 \%$ of their fixation in contrast to the HA-coated screws which retained full fixation strength.

J Bone Joint Surg [Br] 1997;79-B:487-9.

Received 20 August 1996; Accepted after revision 19 November 1996

External fixation is widely used in fracture treatment and bone lengthening, and the mechanical properties of the system and of fixation to bone are important. Animal

G. Magyar, MD, Orthopaedic Surgeon

$\mathrm{S}$. Toksvig-Larsen, MD, PhD, Associate Professor, Orthopaedic Surgeon Department of Orthopedics, University Hospital, Lund S-221 85, Sweden.

A. Moroni, MD, Orthopaedic Surgeon

Rizzoli Orthopaedic Institute, Via G. C. Pupilli 1, Bologna 401 36, Italy.

Correspondence should be sent to Dr G. Magyar.

(c)1997 British Editorial Society of Bone and Joint Surgery 0301-620X/97/37190\$2.00 studies have shown a progressive reduction of pin fixation with time, independent of pin position. ${ }^{1,2}$ Most studies report problems with screw and pin sites, sometimes requiring removal of the external fixation. ${ }^{3,4}$ Mahan et $\mathrm{al}^{5}$ reported a close correlation between loose pins and pin-track inflammation.

In other fields great efforts have been made to enhance bone ingrowth into uncemented surfaces of metallic prostheses. Søballe et al $^{6}$ have shown in animal studies that hydroxyapatite (HA) coating improves fixation under stable-unloaded, stable-loaded and unstable mechanical conditions. HA coating enhanced bone growth, and was shown to convert a motion-induced fibrous membrane into a bony anchorage. ${ }^{7}$ Early clinical results with HA-coated hip prostheses have been promising, ${ }^{8}$ and micromovement studies have shown benefits. ${ }^{9-11}$

We considered that HA coating could improve screw fixation and confirmed good osseointegration in animal studies. ${ }^{12}$ We have now investigated the effect of HA coating of threaded pins in relation to fixation strength and pin-track problems in patients treated by hemicallotasis for medial osteoarthritis of the knee.

\section{PATIENTS AND METHODS}

We studied 19 patients, 12 men and 7 women, of mean age 54 years (38 to 75) with medial osteoarthritis of the knee of Ahlbäck grade 1 to $4,{ }^{13}$ being treated by hemicallotasis. They gave written consent to participation in the study which was approved by our Research Ethical Committee. They were randomised using sealed and numbered envelopes to have either uncoated or HA-coated screws. The tapered screws were otherwise identical and of cortical type (Orthofix 6/5 mm; Orthofix Srl, Bussolengo, Italy; Fig. 1). The HA coating was applied by a plasma-spray technique and was 45 to $70 \mu \mathrm{m}$ thick. The $\mathrm{Ca} / \mathrm{P}$ ratio was 1.658 to 1.700 , the porosity less than $8 \%$, and the bonding strength was $>30 \mathrm{MPa}$. The coating was tested for heavy metals; the levels were below the limits set by the ASTM F1185 standard test (As $<3 \mathrm{ppm}, \mathrm{Cd}<5 \mathrm{ppm}, \mathrm{Hg}<5 \mathrm{ppm}$ and $\mathrm{Pb}$ $<30 \mathrm{ppm}$ ). Hemicallotasis of the proximal tibia involved the use of an external fixator placed anteriorly (Orthofix Tgarche) with two screws inserted parallel to and about $2 \mathrm{~cm}$ below the joint surface, and two in the tibial shaft as shown in Figure 2. The two proximal holes were made with a 


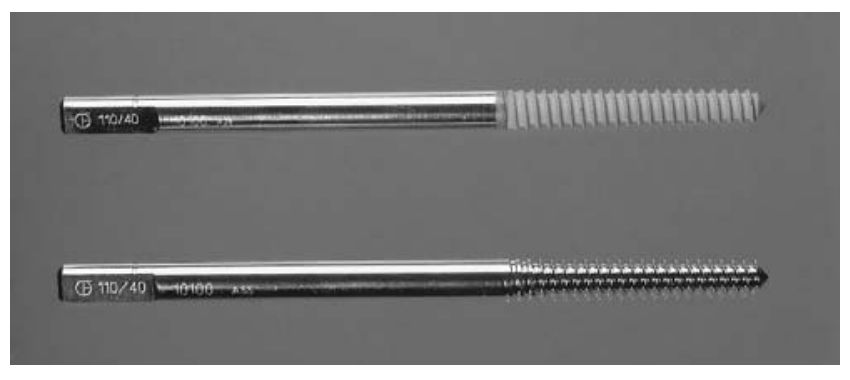

Fig. 1

HA-coated and standard threaded pins.

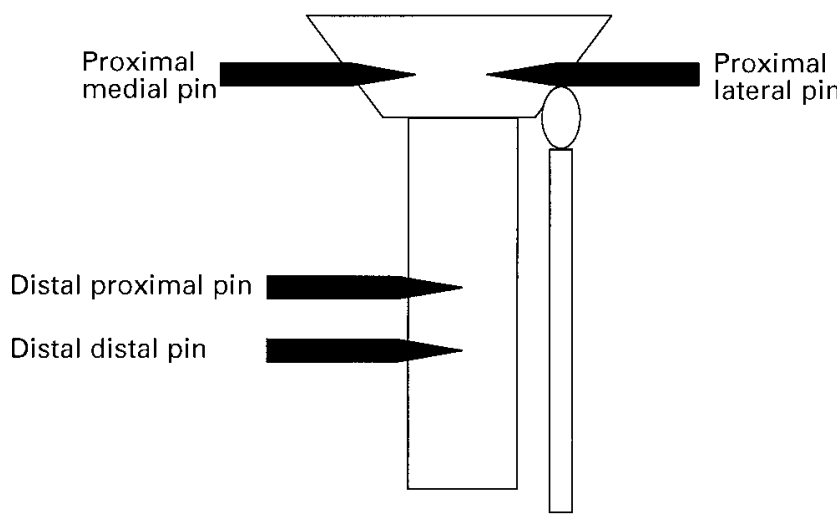

Fig. 2

Diagram to show the position of the four threaded pins (see Table I).

Table I. Mean (Ncm; range) insertion torque force for both types of pin for the four positions shown in Figure 2 (PM, proximal medial pin; PL, proximal lateral pin; DP, distal proximal pin; and DD, distal distal pin)

\begin{tabular}{lll}
\hline Position & Standard & HA-coated \\
\hline PM & $260(90$ to 400$)$ & $207(140$ to 325$)$ \\
PL & $208(50$ to 425$)$ & $201(90$ to 300$)$ \\
DP & $498(400$ to 800$)$ & $538(420$ to 800$)$ \\
DD & $546(420$ to 800$)$ & $488(225$ to 750$)$ \\
\hline
\end{tabular}

Table II. Mean (Ncm; range) of extraction torque forces for both types of pin (PM, proximal medial pin; PL, proximal lateral pin; DP, distal proximal pin; and DD, distal distal pin)

\begin{tabular}{lcll}
\hline Position & Standard & HA-coated & $\begin{array}{l}\text { p values of } \\
\text { difference }\end{array}$ \\
\hline PM & $2(0$ to 10$)$ & $482(0$ to 780$)$ & $<0.001$ \\
PL & $2(0$ to 20$)$ & $478(200$ to 700$)$ & $<0.001$ \\
DP & $277(25$ to 700$)$ & $585(250$ to 800$)$ & 0.003 \\
DD & $249(25$ to 440$)$ & $620(300$ to 800$)$ & $<0.001$ \\
\hline
\end{tabular}

Table III. Evaluation of pain on a VAS scale of 0 to 100 for both types of pin

\begin{tabular}{llll}
\hline Postop week & Standard & HA-coated & p value \\
\hline 1 & $19(0$ to 56$)$ & $16(0$ to 49$)$ & NS \\
2 & $32(0$ to 61$)$ & $37(0$ to 81$)$ & NS \\
3 & $33(0$ to 74$)$ & $30(0$ to 64$)$ & NS \\
4 & $22(0$ to 54$)$ & $16(0$ to 43$)$ & NS \\
9 & $2(0$ to 6$)$ & $4(0$ to 22$)$ & NS \\
12 & $1(0$ to 10$)$ & $3(0$ to 22$)$ & NS \\
\hline
\end{tabular}

$3.2 \mathrm{~mm}$ drill and the distal holes in cortical bone with a $4.8 \mathrm{~mm}$ drill. The osteotomy was at the level of the distal third of the tibial tuberosity, using a pneumatic reciprocal saw. The fixator was locked for the first 7 to 10 days, and angular distraction then started with four quarter-turns daily until the desired correction had been achieved.

The mean fixation time was 101 days (61 to 155 ) and the mean distraction time 16 days (5 to 54 ). Nine patients had HA-coated screws and nine had standard pins. In one patient we used HA-coated screws in the metaphysis, and standard screws in the diaphysis. The torque forces for insertion and extraction were measured by using a torqueforce screwdriver with a range of 0 to $800 \mathrm{Ncm}$. The pin sites were evaluated daily by a nurse, and pain levels were measured by a visual analogue scale (VAS), once daily during the distraction phase and weekly during the healing phase. All screws were removed without need for sedation or local anaesthesia.

For statistical analysis we used the $t$-test for independent samples.

\section{RESULTS}

There were no significant differences between the mean torque forces for insertion, as shown in Table I. By the time of extraction, all 18 of the uncoated metaphyseal screws were loose, as defined by a torque force of $\leq 20 \mathrm{Ncm}$. One of the 20 uncoated diaphyseal screws showed an increased fixation, but the other 19 had extraction torque forces in the diaphysis of about half of the insertion torque force, although none was clinically loose.

In the HA-coated group 19 of the 20 metaphyseal screws showed an increased strength of fixation and one was completely loose. In the diaphysis all 18 screws were well fixed, but in one patient both screws had lost about $40 \%$ of their fixation. The differences in extraction torque force for the two types of screw were highly significant (Table II; $p<0.005)$. We found no correlation between the changes in fixation torque and the duration of fixation.

There were no statistical differences in pain levels (Table III) or in superficial pin-site problems between the two groups and no difference in the amount of antibiotics or analgesics given.

\section{DISCUSSION}

We have shown that the use of HA-coating enhances screw fixation, more in metaphyseal than in diaphyseal bone.

We found no adverse effect of using HA-coated screws, although we had the impression that patients had more pain during extraction of these than those with standard screws. This was never enough to require local anaesthesia or sedation.

The hemicallotasis method of tibial osteotomy for younger patients with medial osteoarthritis has the potential for greater precision and less morbidity than the conventional closed- 
wedge method. One major concern about the use of this technique is the incidence of pin-site problems, especially in the metaphysis in close relation to the joint itself. Different studies have reported a frequency of minor pin-track infection from $5 \%$ to $58 \%$ and of major pin-track infections from $2 \%$ to $20 \% .^{3,4,14}$ It is generally accepted that a loose pin provides an increased risk of infection, 3,5 and it seems that HA-coated pins could probably reduce this risk.

The benefits of the well-fixed HA pins included tendencies towards less pain and less pin-track inflammation during distraction and the healing phase, although our small series did not show any statistical significance. Factors which affect the bone-implant interface and its stability include the surgical technique, the initial apposition fit, ${ }^{15}$ movement at the interface, ${ }^{16}$ the quality and metabolic status of the host bone and any bioactivity of the implant surface and coating. The design of the screw threads affects the fixation, and there is also the possibility of thermal injury during drilling. ${ }^{17}$ Theoretically, the insertion torque force for an HA-coated screw should be greater because of its rougher surface, but our study failed to confirm this. The increased roughness of the HA coating may, indeed, contribute to better initial fixation. Under the ideal interface conditions with a tight interference fit, minimal motion and no direct loading, HA coating is known to enhance host tissue reaction and early fixation. Ideal interface conditions are not always attainable, but HA coating has also been shown to improve fixation even under suboptimal interface conditions. ${ }^{6}$ We used a model with very high demands on the screw-bone interface, since we allowed full weight-bearing during treatment and performed hemicallotasis, but in these conditions hydroxyapatite clearly enhanced the fixation. We therefore recommend the use of HA-coated pins.

We wish to thank Stiftelsen för bistånd åt vanfo̊ra i Skåne, MFR (09509), Malmo̊hus Läns Landsting, Lunds Sjukvårdsdistrikt.

No benefits in any form have been received or will be received from a commercial party related directly or indirectly to the subject of this article.

\section{REFERENCES}

1. Aro HT, Markel MD, Chao EY. Cortical bone reactions at the interface of external fixation half-pins under different loading conditions. J Trauma 1993;35:776-85.

2. Pettine KA, Chao EY, Kelly PJ. Analysis of the external fixator pinbone interface. Clin Orthop 1993;293:18-27.

3. Green SA. Complications of external skeletal fixation. Clin Orthop 1983;180:109-16.

4. Pouliquen JC, Ceolin JL, Langlais J, Pauthier F. Upper metaphyseal lengthening of the tibia by callotasis: forty-seven cases in children and adolescents. J Pediatr Orthop 1993;2:49-56.

5. Mahan J, Seligson D, Henry SL, Hynes P, Dobbins J. Factors in pin tract infections. Orthopedics 1991;14:305-8.

6. Søballe K, Hansen ES, Brockstedt-Rasmussen H, Bünger C. Tissue ingrowth into titanium and hydroxyapatite coated implants during stable and unstable mechanical conditions. J Orthop Res 1992;10:285-99.

7. Søballe K, Hansen ES, Brockstedt-Rasmussen H, Bünger C. Hydroxyapatite coating converts fibrous tissue to bone around loaded implants. J Bone Joint Surg [Br] 1993;75-B:270-8.

8. Geesink RGT. Hydroxyapatite-coated total hip prostheses: 2 year clinical and roentgenographic results of 100 cases. Clin Orthop 1990;261:39-58.

9. Kroon P-O, Freeman MAR. Hydroxyapatite coating on hip prostheses: effect on migration into the femur. J Bone Joint Surg $[\mathrm{Br}]$ 1992;74-B:518-22.

10. Kärrholm J, Snorrason F. Subsidence, tip, and hump micromovements of noncoated ribbed femoral prostheses. Clin Orthop 1993;287:50-60.

11. Søballe $\mathbf{K}$, Toksvig-Larsen $\mathbf{S}$, Gelineck $\mathbf{J}$, et al. Migration of hydroxyapatite coated femoral stems: a roentgen stereophotogrammetric study. J Bone Joint Surg [Br] 1993;75-B:681-7.

12. Moroni A, Caja VL, Maltarello C, et al. Enhancement of the bone external fixation pin interface: a biomechanical and morphological in vivo experimental study. Bioceramics 1994;7:229-34.

13. Ahlbäck S. Osteoarthrosis of the knee: a radiographic investigation. Acta Radiol 1968; Suppl 277:7-72.

14. Haugegaard M, Albrecht-Olsen P. Occurrence of infection when using Ortofix. Acta Orthop Scand 1993;64,suppl 253:41.

15. Carlsson L, Röstlund T, Albrektsson B, Albrektsson T. Implant fixation improved by close fit: cylindrical implant-bone interface studied in rabbits. Acta Orthop Scand 1988;59:272-5.

16. Aspenberg P, Goodman S, Toksvig-Larsen S, Ryd L, Albrektsson T. Intermittent micromotion inhibits bone ingrowth: titanium implants in rabbits. Acta Orthop Scand 1992;63:141-5.

17. Wikenheiser MA, Markel MD, Lewallen DG, Chao EY. Thermal response and torque resistance of five cortical half-pins under simulated insertion technique. J Orthop Res 1995;13:615-9. 